\title{
Enhanced Thermoelectric Transport Properties of $n$-type InSe by Sn doping
}

\author{
Sung-sil Choo ${ }^{1, \uparrow}$, Seok-won Hong ${ }^{1, \uparrow}$, Hyun-Sik Kim², and Sang-il Kim ${ }^{1, *}$ \\ ${ }^{I}$ Department of Materials Science and Engineering, University of Seoul, Seoul 02504, Republic of Korea \\ ${ }^{2}$ Department of Materials Science and Engineering, Hongik University, Seoul 04066, Republic of Korea
}

\begin{abstract}
Layered post transition metal chalcogenides such as $\mathrm{SnSe}, \mathrm{SnSe}_{2}, \mathrm{In}_{2} \mathrm{Se}_{3}$, and $\mathrm{In}_{4} \mathrm{Se}_{3}$ have attracted attention as promising thermoelectric materials due to their intrinsically low lattice thermal conductivities. Recently, $n$-type indium selenide (InSe) based materials have also been suggested as good candidates for thermoelectric materials by optimizing their electrical properties, i.e., increasing carrier concentration. Here, we report enhancement of the thermoelectric properties of $n$-type InSe by Sn substitutional doping at the In site. A series of $\operatorname{In}_{1-\mathrm{x}} \mathrm{Sn}_{\mathrm{x}} \mathrm{Se}$ for $\mathrm{x}=0,0.03,0.05,0.15$ and 0.2 was examined. The carrier concentration and electrical conductivity increased due to the Sn substitution, since Sn behaves as a shallow electron donor in InSe, while the Seebeck coefficient decreased moderately. In addition, it was found that effective mass was increased by more than 10 times by Sn doping. As a result, the power factor was enhanced from $0.07 \mathrm{~mW} /$ $\mathrm{mK}^{2}$ to $0.13 \mathrm{~mW} / \mathrm{mK}^{2}$ at $800 \mathrm{~K}$. The total thermal conductivity was unchanged despite $\mathrm{Sn}$ doping because the electrical contribution to the total thermal conductivity was very small. Consequently, Sn doping in InSe enhanced the dimensionless thermoelectric figure of merit $z T$ from 0.04 to 0.14 at $800 \mathrm{~K}$, mainly due to enhanced electrical properties.
\end{abstract}

(Received April 6, 2020; Accepted April 8, 2020)

Keywords: InSe, thermoelectric, chalcogenide, doping, density-of-states effective mass

\section{INTRODUCTION}

Thermoelectric materials can convert temperature gradients into electrical potential and vice versa. A high thermoelectric conversion efficiency is required to utilize the potential created from waste heat generated in various industries and automobiles. The thermoelectric conversion efficiencies are evaluated using a dimensionless thermoelectric figure-of-merit, $z T=S^{2} \sigma T / \kappa$, where $S, \sigma, \kappa$ and $T$ are the Seebeck coefficient, the electrical conductivity, the total thermal conductivity and the absolute temperature, respectively. Accordingly, a high power factor $S^{2} \sigma$ or low $\kappa$ is required for thermoelectric materials to achieve a high $z T[1,2]$. Conventional thermoelectric materials such as $\mathrm{Bi}_{2} \mathrm{Te}_{3}$ [3], $\mathrm{PbTe}$ [4] and $\mathrm{CoSb}_{3}$ [5] have been widely studied for decades in efforts to improve their thermoelectric performance. Nanostructuring [6], doping [7] and carrier

- 추성실: 연구원, 홍석원: 석사과정, 김현식 - 김상일: 교수

$\dagger$ These authors contributed equally to this work

*Corresponding Author: Sang-il Kim

[Tel: +82-2-6490-2414, E-mail: sang1.kim@uos.ac.kr ]

Copyright (C) The Korean Institute of Metals and Materials filtering [8] have been considered effective approaches to enhance $z T$ by either increasing the power factor or reducing $\kappa$. Meanwhile, other efforts have been focused on discovering new thermoelectric materials. Among the various new thermoelectric materials, post-transition metal chalcogenides such as SnSe [9], $\mathrm{In}_{4} \mathrm{Se}_{3}$ [10] and $\mathrm{In}_{2} \mathrm{Se}_{3}$ [11], which consist of a two-dimensional layered structure, have attracted significant attention due to their intrinsically low lattice thermal conductivity $\left(\kappa_{\text {latt }}\right)$, which is caused by the weak atomic bonding between layers (van der Waals bonds). Additionally, SnSe and $\mathrm{In}_{4} \mathrm{Se}_{3}$ materials exhibit a special phenomenon in which lattice softening [9] of the charge density wave (CDW) [10] occurs as the temperature increases. This greatly reduces the lattice thermal conductivity, $\kappa_{\text {latt }}$. Because of these properties, post-transition metal chalcogenides have been studied as potential thermoelectric materials.

The post transition metal indium selenide ( $\mathrm{InSe}$ ) is a III-VI group semiconductor with a band gap of $\sim 1.2 \mathrm{eV}$. It exhibits a strong covalent bond within layers and a weak van der Waals bond between layers. Due to the weak van der Waals bond between the layers, the reported thermal conductivity of 
an InSe crystal in directions parallel and perpendicular to the $c$-axis was 0.37 and $1.2 \mathrm{~W} / \mathrm{mK}$, respectively $[12,13]$. These results suggest InSe-based alloys may be good candidates to achieve high $z T$ by optimizing electrical properties such as carrier concentration, mobility and band structure. In previous studies, substitutes like $\mathrm{Si}, \mathrm{Sn}$ and As have been suggested as shallow donors [14]. Lee et al. reported that $\mathrm{Si}$ acts as a shallow donor in InSe, to modify the electronic structure including the carrier concentration and mobility [15]. Anion doping of Se/Te in InSe also increased the carrier concentration [16]. Therefore, we suggested the possibility that group IV elements such as Ge and Sn could enhance the electrical properties of InSe.

In this study, we investigated the influence of Sn doping (a group IV element), which acted as a shallow donor in InSe, to enhance electrical properties. We synthesized a series of Sn-doped InSe $\left(\operatorname{In}_{1-\mathrm{x}} \mathrm{Sn}_{\mathrm{x}} \mathrm{Se}, \mathrm{x}=0,0.03,0.05,0.15\right.$ and 0.2) polycrystalline samples. Sn doping significantly increased the carrier concentration while reducing mobility only to a certain extent. As a result, the $\sigma$ largely increased while the $S$ was moderately reduced, thus enhancing the power factor. Regardless of the increase in the $\sigma$, $\kappa$ hardly changed with $\mathrm{Sn}$ doping due to the negligible electronic contribution in $\kappa$. As a result, the value of $z T$ for the Sn-doped InSe sample increased to 0.14 as compared to a $z T$ value of 0.04 for the pristine InSe.

\section{EXPERIMENT}

A series of $\operatorname{In}_{1-\mathrm{x}} \mathrm{Sn}_{\mathrm{x}} \mathrm{Se}$ compositions with nominal $\mathrm{x}=0$,
$0.03,0.05,0.15$ and 0.2 were synthesized by a conventional solid-state reaction in a vacuum-sealed quartz tube with stoichiometric compositions. Stoichiometric amounts of In, Sn and Se powders (In: $99.995 \%$, Sn: $99.995 \%$, Se: $99.999 \%$ ) were mixed and reacted in a fused vacuum quartz tube at $500{ }^{\circ} \mathrm{C}$ for $48 \mathrm{~h}$. The synthesized ingots were ground into powders using a mortar. The polycrystalline samples were compacted using spark plasma sintering (SPS) at $430{ }^{\circ} \mathrm{C}$ for 5 min under $70 \mathrm{MPa}$.

The crystalline phases of the samples were identified using X-ray diffraction (XRD) with $\mathrm{Cu} \mathrm{K}_{\alpha}$. The $\sigma$ and $S$ were measured simultaneously using a thermoelectric property measurement system, ZEM-3, perpendicular to the pressing direction, as the temperature was increased from 300 to $800 \mathrm{~K}$. The Hall measurement was performed in the van der Pauw configuration using a Hall measurement system, from room temperature to $500 \mathrm{~K}$. The $\kappa$ was calculated using the relationship $\kappa=\rho_{\mathrm{s}} \cdot C_{\mathrm{p}} \cdot \lambda$, where $\rho_{\mathrm{s}}, C_{\mathrm{p}}$, and $\lambda$ are the sample density, heat capacity, and thermal diffusivity, respectively. The $\lambda$ was measured using a laser-flash method, perpendicular to the pressing direction, as the temperature was increased from 300 to $800 \mathrm{~K}$. The theoretical density of each sample with nominal composition was used to calculate $\kappa$. Further, the value of $C_{\mathrm{p}}$ of InSe was considered to be $0.255 \mathrm{~J} / \mathrm{g} \cdot \mathrm{K}$ for all the samples.

\section{RESULTS AND DISCUSSION}

Figures 1(a) and 1(b) show the XRD patterns and the calculated lattice parameters for a series of Sn-doped InSe
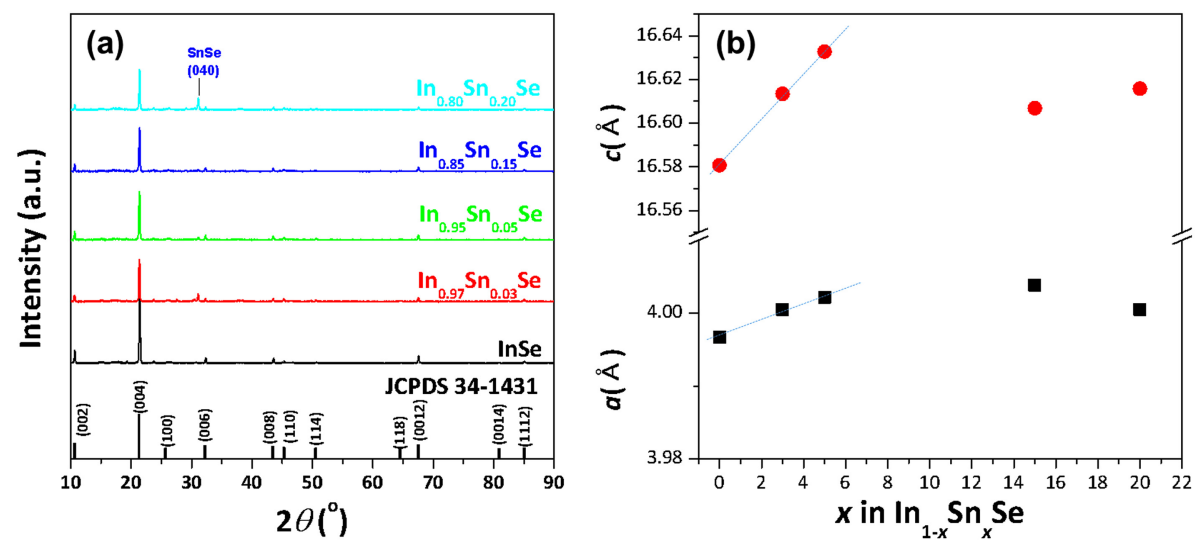

Fig. 1. (a) the XRD patterns and (b) the calculated lattice parameters for a series of $\mathrm{Sn}$-doped $\operatorname{InSe}\left(\operatorname{In}_{1-\mathrm{x}} \mathrm{Sn}_{\mathrm{x}} \mathrm{Se}, \mathrm{x}=0,0.03,0.05,0.15\right.$ and $0.2)$ polycrystalline samples. 
$\left(\operatorname{In}_{1-\mathrm{x}} \mathrm{Sn}_{\mathrm{x}} \mathrm{Se}, \mathrm{x}=0,0.03,0.05,0.15\right.$ and 0.2$)$ polycrystalline samples. As seen in Figure 1(a), single-phase InSe samples were successfully synthesized. The SnSe impurity was observed rather intensively for $\operatorname{In}_{0.8} \mathrm{Sn}_{0.2} \mathrm{Se}$. The lattice parameters, $a$ and $c$, are as shown in Figure 1(b). The values of $a$ and $c$ increased continuously for $\mathrm{x}=0,0.03$, and 0.05 because the ionic radius of $\operatorname{In}^{2+}(80 \mathrm{pm})$ was smaller than that of $\mathrm{Sn}^{2+}(93 \mathrm{pm})$. The continuous change in the lattice parameters indicated that substitutional doping of Sn at the In site was successful. Beyond $\mathrm{x}=0.05$, the second phase of SnSe precipitated and complete doping was not achieved; moreover, the lattice parameters changed rather irregularly. Therefore, the characterization was only performed for the small doping samples $(\mathrm{x}=0,0.03$, and 0.05).

Figure 2(a) shows the $\sigma$ as a function of temperature for a series of $\mathrm{Sn}$-doped $\mathrm{InSe}\left(\operatorname{In}_{1-\mathrm{x}} \mathrm{Sn}_{\mathrm{x}} \mathrm{Se}, \mathrm{x}=0,0.03,0.05\right)$ samples. It can be observed that the value of $\sigma$ increases as the temperature increases, which is a typical behavior of a non-degenerated semiconductor. The $\sigma$ values at room
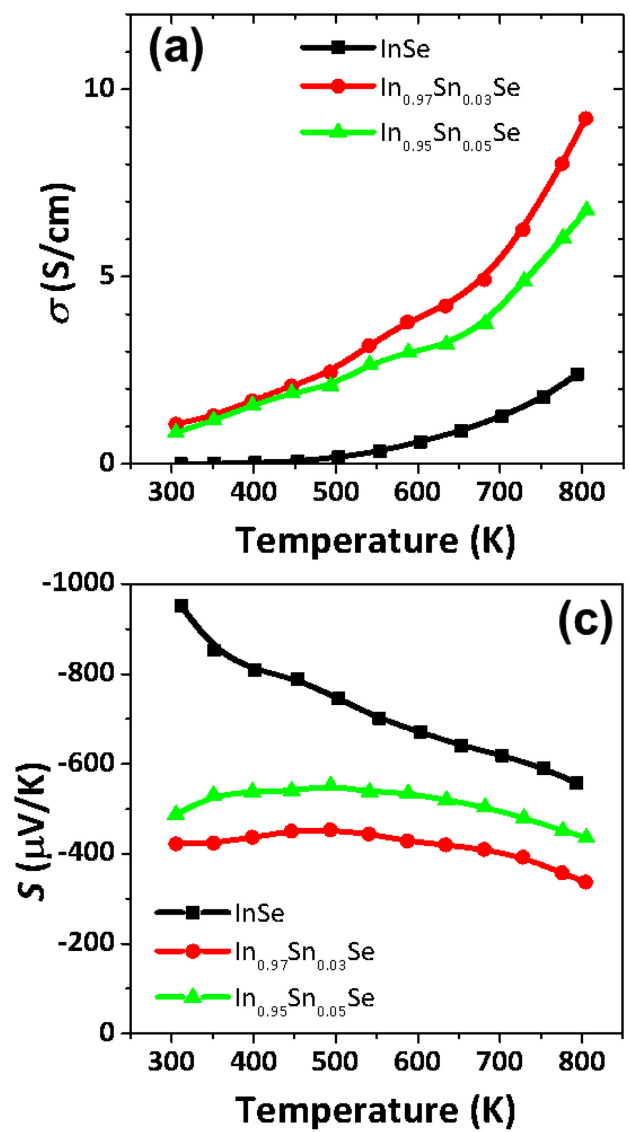

temperature were $0.001,1.063$ and $0.839 \mathrm{~S} / \mathrm{cm}$ for $\mathrm{x}=0,0.03$, and 0.05 in $\operatorname{In}_{1-\mathrm{x}} \mathrm{Sn}_{\mathrm{x}} \mathrm{Se}$, respectively, which generally increased with $\mathrm{Sn}$ doping. At $800 \mathrm{~K}, \sigma$ increased to a maximum value of $9.221 \mathrm{~S} / \mathrm{cm}$ for $x=0.03$. Figure 2(b) shows the logarithm of $\sigma$ as a function of $1000 / T$, which indicates that the transport mechanism is changing around $660 \mathrm{~K}$ (where 1000/ $T$ is $\sim 1.5$ ). The activation energy $\left(E_{a}\right)$ for $\sigma$ as a function of temperature based on the Arrhenius`s relationship ( $\sigma \propto$ exp $\left(-E_{a} / k T\right)$, where $k$ and $T$ are the Boltzmann constant and absolute temperature, respectively) changes around $660 \mathrm{~K}$. When InSe is doped with $\mathrm{Sn}, E_{a}$ decreases as seen in Figure 2(b), which means that the ratio of increase in $\sigma$ to the increase in temperature is higher at all temperatures for the Sn-doped sample, as compared to that of the pristine InSe.

Figure 2(c) and (d) show the $S$ and the power factor as a function of temperature for a series of $\mathrm{Sn}$-doped $\mathrm{InSe}\left(\mathrm{In}_{1-}\right.$ $\left.{ }_{\mathrm{x}} \mathrm{Sn}_{\mathrm{x}} \mathrm{Se}, \mathrm{x}=0,0.03,0.05\right)$ samples. Due to the inverse relationship between $\sigma$ and $S$, the value of $S$ for pristine InSe $(-952.5 \mu \mathrm{V} / \mathrm{K})$ when doped with $\mathrm{Sn}$ decreased to -422.6 and
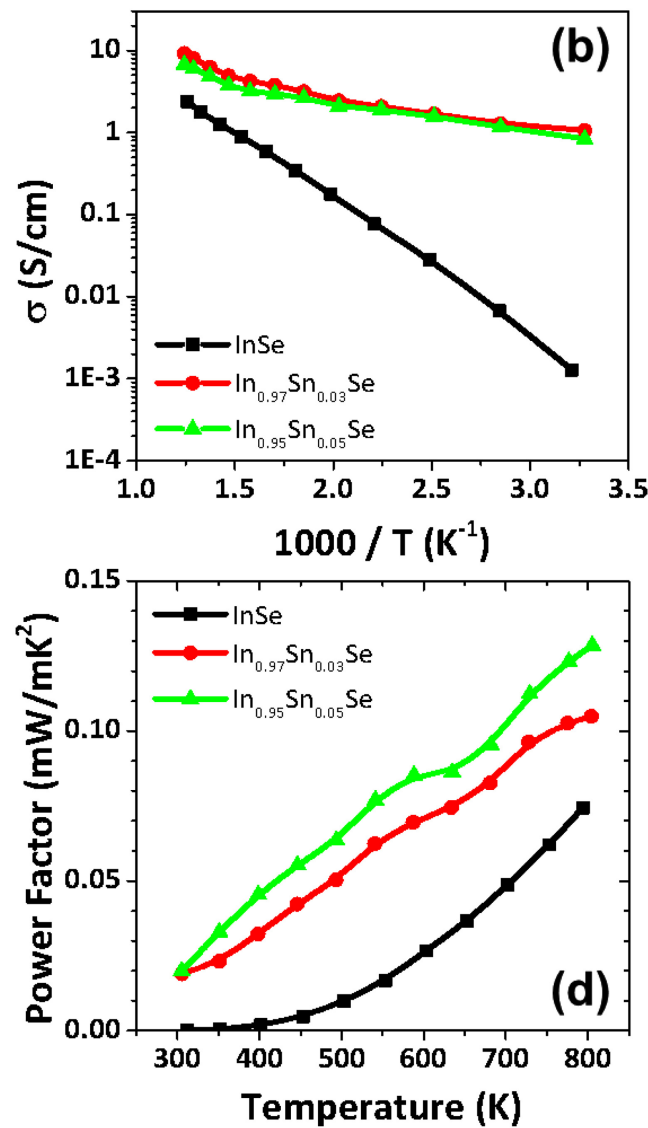

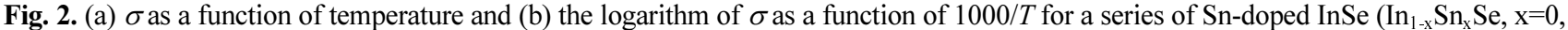
$0.03,0.05)$ samples. (c) $S$ and (d) power factor of $S n$-doped $I n S e\left(\operatorname{In}_{1-\mathrm{x}} \mathrm{Sn}_{\mathrm{x}} \mathrm{Se}, \mathrm{x}=0,0.03,0.05\right)$ samples. 
$-488.1 \mu \mathrm{V} / \mathrm{K}$ for $\mathrm{x}=0.03$ and 0.05 at room temperature, respectively. The power factor increased when doped with $\mathrm{Sn}$ due to an increase in $\sigma$, at $800 \mathrm{~K}$, a maximum value of 0.13 $\mathrm{mW} / \mathrm{mK}^{2}$ at $\mathrm{x}=0.05$ in $\mathrm{In}_{1-\mathrm{x}} \mathrm{Sn}_{\mathrm{x}} \mathrm{Se}$ was observed.

The carrier concentration and mobility of a series of Sndoped $\operatorname{InSe}\left(\operatorname{In}_{1-\mathrm{x}} \mathrm{Sn}_{\mathrm{x}} \mathrm{Se}, \mathrm{x}=0,0.03,0.05\right)$ samples are depicted in Figure 3(a) and (b). The carrier concentration significantly increased from $0.0021 \times 10^{16}$ for $\mathrm{x}=0$ to $7.12 \times 10^{16}$ for $\mathrm{x}=0.03$ and $3.69 \times 10^{16}$ for $\mathrm{x}=0.05$ at $300 \mathrm{~K}$. Since the Sn impurity acted as a shallow donor in InSe, the carrier concentration could be extensively generated [14]. On the other hand, the mobility changed slightly, such that it increased at low temperatures and decreased at high temperatures.

Figure 3(c) shows the values of $S$ as a function of the electron concentration (Pisarenko plot) at $300 \mathrm{~K}$ for the $\mathrm{Sn}$ doped samples. The dotted curves are plotted for effective mass $\left(m^{*}\right.$, expressed with respect to $\left.m_{\mathrm{o}}\right)$ of $0.001,0.01$ and 0.1 using the Mott-relation [17], expressed by Equation (1):

$$
S=\frac{8 \pi^{2} k^{2}}{3 e h^{2}}\left(\frac{\pi}{3 n}\right)^{2 / 3} m^{*} T
$$

where $e, h$, and $n$ are the elementary charge, the Planck constant, and the carrier concentration, respectively. When doped with Sn, the $m^{*}$ became more than 10 times higher than that of pristine InSe.

Figure 4(a) shows the values of $\kappa$ for a series of Sn-doped InSe $\left(\operatorname{In}_{1-\mathrm{x}} \mathrm{Sn}_{\mathrm{x}} \mathrm{Se}, \mathrm{x}=0,0.03,0.05\right)$ samples, which did not change much with doping. At $300 \mathrm{~K}$, the $\kappa$ values were 1.8 , 1.9 and $1.8 \mathrm{~W} / \mathrm{mK}$ for $\mathrm{x}=0,0.03$ and 0.05 , respectively. The increase in $\sigma$ would raise the electronic contribution, i.e., the electronic thermal conductivity $\left(\kappa_{\text {elec }}\right)$, since $\kappa_{\text {elec }}$ is proportional to the $\sigma$. However, the $\kappa$ was almost unchanged despite the $\sigma$ increase because $\kappa_{\text {elec }}$ was less than about $1 \%$ of $\kappa$.
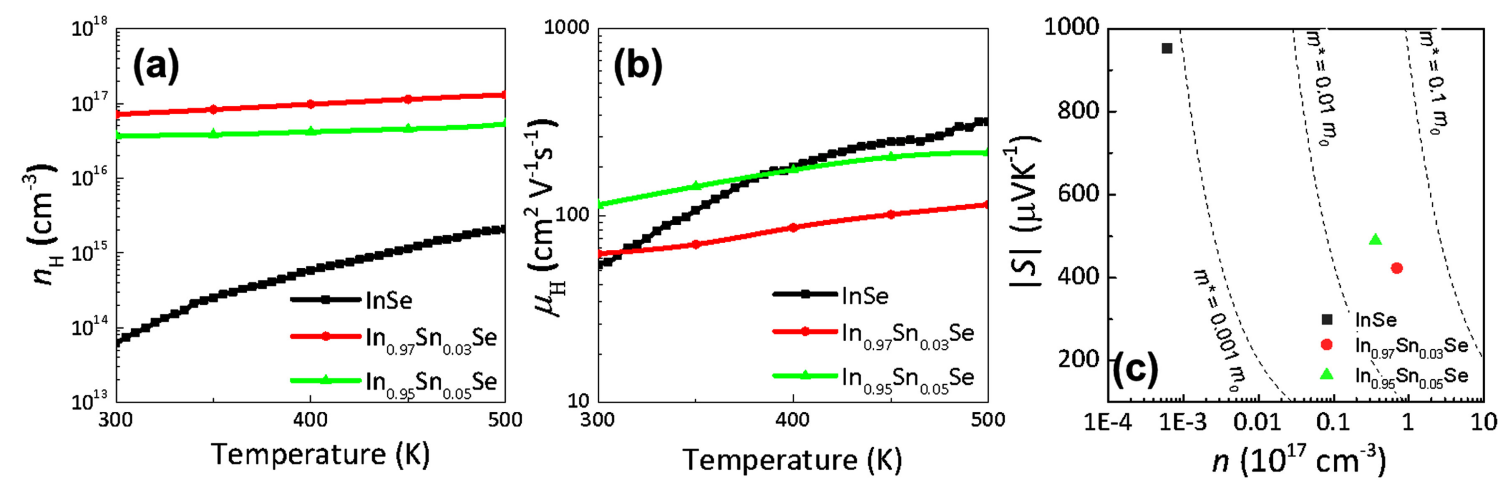

Fig. 3. (a) Carrier concentration and (b) mobility measured using Hall measurement for a series of $S n$-doped $\operatorname{InSe}_{\left(n_{1-x}\right.} \operatorname{Sn}_{x} S e, x=0,0.03$, $0.05)$ samples. (c) Pisarenko Plots for a series of Sn-doped InSe $\left(\operatorname{In}_{1-\mathrm{x}} \mathrm{Sn}_{\mathrm{x}} \mathrm{Se}, \mathrm{x}=0,0.03,0.05\right)$ samples. The effective mass $m^{*}$ increased more than 10 times with Sn doping.
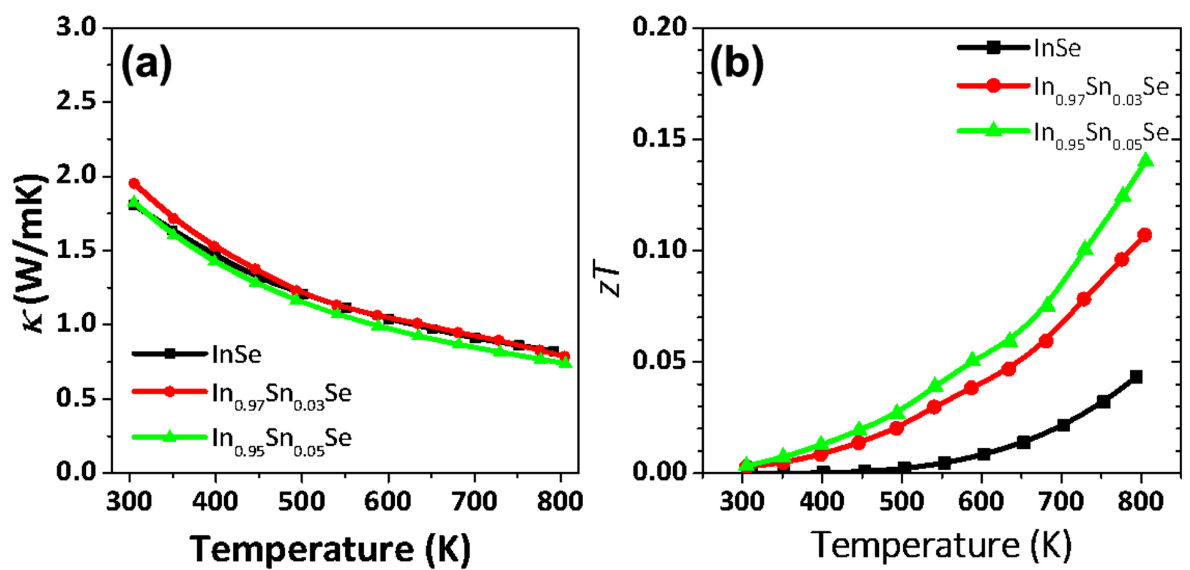

Fig. 4. (a) $k$ and (b) $z T$ as a function of temperatures for a series of $S n$-doped $I n S e\left(\operatorname{In}_{1-\mathrm{x}} \mathrm{Sn}_{\mathrm{x}} \mathrm{Se}, \mathrm{x}=0,0.03,0.05\right)$ samples. 
Using the measured values of $\sigma, S$, and $k$ for the pristine InSe and the Sn-doped InSe samples, the value of $z T$ was calculated and is shown in Figure 4(b). At $800 \mathrm{~K}$, the $z T$ values were 0.04 for pristine $\mathrm{InSe}$ and 0.11 and 0.14 for $\mathrm{x}=0.03$ and 0.05 samples, respectively. The $z T$ values of the Sn-doped InSe samples increased compared to that of the pristine InSe. The enhancement in $z T$ was attributed to the increase in $\sigma$ due to the significantly increased electron concentration. As a result, it was concluded that $\mathrm{Sn}$ substitution in InSe behaved as a shallow donor in InSe and enhanced electrical properties and the $z T$.

\section{CONCLUSION}

We measured the electrical and thermal transport properties of a series of $\mathrm{Sn}$-doped $\operatorname{InSe}\left(\operatorname{In}_{1-\mathrm{x}} \mathrm{Sn}_{\mathrm{x}} \mathrm{Se}, \mathrm{x}=0,0.03,0.05\right)$ samples to explore the effects of $\mathrm{Sn}$ doping on InSe. The $\mathrm{Sn}$ doping significantly increased the carrier concentration and the electrical conductivity, as the substituted Sn acted as a shallow donor. Although the Seebeck coefficient decreased due to an inverse relationship with the carrier concentration, the power factor was effectively enhanced as a result of an increase in the effective mass of the Sn-doped samples. The thermal conductivity was unchanged because the electronic contribution to thermal conductivity was negligible. Consequently, the Sn doping in InSe enhanced the value of $z T$ from 0.04 to 0.14 at $800 \mathrm{~K}$ when doped with $\mathrm{Sn}$ (at $\mathrm{x}=0.05$ ).

\section{Acknowledgements}

This research was supported by the National Research Foundation of Korea (NRF) (NRF-2019R1C1C1005254).
1. L. E. Bell, Science 321, 1457 (2008).

2. G. J. M. Velders, A. R. Ravishankara, M. K. Miller, M. J. Molina, J. Alcamo, J. S. Daniel, D. W. Fahey, S. A. Montzka, and S. Reimann, Science 335, 922 (2012).

3. H. Scherrer and S. Scherrer, in Thermoelectrics Handbook: Macro to Nano, pp.1-27, CRC press, Boca Raton (2006).

4. Z. H. Dughaish, Phys. B 322, 205 (2002).

5. Y. Kawaharada, K. Kurosaki, M. Uno, and S. Yamanaka, J. Alloys Compd. 315, 193 (2001).

6. S. I. Kim, K. H. Lee, H. A. Mun, H. S. Kim, S. W. Hwang, J. W. Roh, D. J. Yang, W. H. Shin, X. S. Li, and Y. H. Lee, Science 348, 109 (2015).

7. W.-J. Jung, I.-H. Kim, Met. Mater. Int. 24, 404 (2018)

8. K. Kishimoto, M. Tsukamoto, and T. Koyanagi, J. Appl. Phys. 92, 1 (2002).

9. S. T. Lee and Y. S. Lim, Korean J. Met. Mater. 56, 163 (2018).

10. J. S. Rhyee, K. H. Lee, S. M. Lee, E. Cho, S. I. Kim, E. Lee, Y. S. Kwon, J. H. Shim, and G. Kotliar, Nature 459, 965 (2009).

11. J. Cui, L. Wang, P. Ying, and Y. Deng, J. Mater. Chem. 35, 9069 (2015).

12. D. P. Spitzer, J. Phys. Chem. 31, 19 (1970).

13. X. Hou, S. Chen, Z. Du, X. Liu, and J. Cui, RSC Adv. 5, 102856 (2015).

14. S. Shigetomi, J. Appl. Phys. 93, 2301 (2003).

15. K. H. Lee, M. W. Oh, H. S. Kim, W. H. Shin, K. M. Lee, J. H. Lim, J. I. Kim, and S. I. Kim, Inorg. Chem. Front. 6, 1475 (2019).

16. J. I. Kim, H. S. Kim, and S. I. Kim, J. Phys. D 52, 205501 (2019).

17. M. Jonson and G. D. Mahan, Phys. Rev. B 21, 4223 (1980).

\section{References}

